\title{
O PROTAGONISMO DAS PRINCESAS AFRICANAS NA LITERATURA JUVENIL: UMA INVESTIGAÇÃO NO PNBE
}

\author{
RENATA JUNQUEIRA DE SOUZA ${ }^{1}$ \\ DANIELA MARIA SEgABINAZI ${ }^{2}$ \\ JHENNEFER ALVES MACÊDO ${ }^{3}$
}

RESUMO: Este artigo é uma reflexão que aborda e discute o protagonismo das princesas negras nas publicações contemporâneas, particularmente após a Lei 10.639/03. Nesse recorte, o principal objetivo é apresentar o levantamento bibliográfico realizado em todas as edições do Programa Nacional da Biblioteca Escolar (PNBE) para os anos finais do ensino fundamental e analisar as contribuições que essas narrativas estão proporcionando para o (re)conhecimento da memória das princesas africanas. $O$ aporte teórico são os estudos de Oliveira (2008) e Paiva e Soares (2014), que apontam os avanços e inquietações que a lei representa no tocante à legitimação da literatura afro-brasileira. Nesse primeiro estudo, já foi possível localizar algumas narrativas escritas por brasileiros que estão adaptando os contos populares africanos e/ou afro-brasileiros e revelam as histórias das princesas africanas que "supostamente" existiram, mas que ficaram esquecidas na história e memória dos leitores.

Palavras-chave: Literatura juvenil. Literatura Afro-brasileira. Princesas africanas.

THE PROTAGONISM OF AFRICAN PRINCESS IN YOUNG LITERATURE: AN INVESTIGATION IN $P N B E$

ABSTRACT: This paper is a reflection that approach and discuss the protagonist of black princess in contemporary publications, especially after the law $10.639 / 03$. In this part, the main purpose is show the bibliographic survey carried out in all the edition of Programa Nacional da Biblioteca Escolar (PNBE) for the final years of elementary school and analyze the contributions of these narratives are providing to (re) knowledge of memory of African princess. The theoretical approaches are the studies of Oliveira (2008) and Paiva and Soares (2014) which indicate the progress and concerns that the law represents regarding the legitimation of afro-Brazilian literature. In this first study, it has already been possible to locate some narratives written by Brazilian who are adapting African and /or afrobrazilian folk tales and reveal the stories of African princess who "apparently" existed, but they were forgotten in history and memory of the readers.

Keywords: Young Literature. Afro-Brazilian Literature. African Princesses.

\footnotetext{
1 Docente da graduação e pós-graduação da Faculdade de Ciências e Tecnologia da UNESP (Presidente Prudente).

2 Professora Doutora da Universidade Federal da Paraíba (UFPB).

3 Mestranda no Programa de Pós-Graduação em Letras (PPGL) da UFPB.
} 


\section{PROTAGONISMO DE LAS PRINCESAS AFRICANAS EN LA LITERATURA JUVENIL: INVESTIGACIÓN EN EL PNBE}

RESUMEN: Este artículo es una reflexión que aborda y discute el protagonismo de las princesas negras en las publicaciones contemporáneas, particularmente después de la Ley $10.639 / 03$. En ese recorte, el principal objetivo es presentar el levantamiento bibliográfico realizado en todas las ediciones del Programa Nacional de la Biblioteca Escolar (PNBE) para los años finales de la enseñanza fundamental y analizar las contribuciones que esas narrativas están proporcionando para el (re) conocimiento de la memoria de las princesas africanas. El aporte teórico son los estudios de Oliveira (2008) y Paiva y Soares (2014), que apuntan los avances e inquietudes que la ley representa en lo tocante a la legitimación de la literatura afrobrasileña. En ese primer estudio, ya fue posible localizar algunas narrativas escritas por brasileños que están adaptando los cuentos populares africanos y / o afrobrasileños y revelan las historias de las princesas africanas que "supuestamente" existieron, pero que quedaron olvidadas en la historia y memoria de los lectores.

Palabras clave: Literatura juvenil. Literatura Afrobrasileña. Princesas africanas.

\section{Acervos do PNBE: a presença dos personagens negros nas narrativas juvenis}

Nos últimos anos, estamos envoltos em discussões que tratam da recém-inclusão das temáticas de literatura africana e afro-brasileira no mercado editorial de livros literários. Inúmeros estudos têm congregado discussões, a fim de averiguar como as políticas públicas de leitura têm se adequado frente às exigências dispostas pela Lei 10.639/034 .

Um importante suporte para a propagação dessas temáticas africanas e afro-brasileiras são os acervos enviados para as escolas por meio de importantes políticas públicas de leitura. Em entrevista concedida a Nascimento (2003, p. 52), Marisa Lajolo destaca que "a relação entre literatura infantil, literatura juvenil e escola vem desde o nascimento desses gêneros e está cada vez mais entrelaçada". Grande parte dos livros produzidos pelas editoras é comprada pelo governo e enviada às escolas públicas e, para isto, acontece uma seleção criteriosa dos títulos. É fundamental, nesse cenário de compras de acervos a serem enviados às escolas, levantar dados referentes às políticas públicas de leitura e aos programas governamentais de incentivo à leitura escolar no Brasil, assim como mapear e analisar os critérios levados em consideração pelas instâncias governamentais na escolha

4 A Lei 10.639/03 versa sobre o ensino da história e cultura africana e afro-brasileira e ressalta a importância da cultura negra na formação da sociedade

brasileira. 
dessas obras literárias.

No Brasil, várias políticas públicas de leitura foram implementadas, possuindo um objetivo em comum entre elas, que é a formação de leitores em nosso país. Diante da necessidade de livros literários de qualidade nas escolas públicas, o Programa Nacional Biblioteca na Escola (PNBE) foi criado no ano de 1997, tendo como principal objetivo promover o acesso à cultura e à leitura nas escolas públicas. O PNBE era executado pelo Fundo Nacional de Desenvolvimento da Educação (FNDE), em parceria com a Secretaria da Educação Básica (SEB) do Ministério da Educação (MEC), e consistia em um Programa que selecionava, adquiria e distribuía obras de literatura e de referência às escolas públicas de Educação Infantil, de Ensino Fundamental, anos iniciais e anos finais e, a partir de 2008, também de Ensino Médio, Educação de Jovens e Adultos e Educação Especial (EJA).

Para iniciarmos a discussão acerca da representatividade das temáticas da história e cultura afro-brasileiras e africanas nas narrativas literárias destinadas ao público juvenil, realizaremos um mapeamento dos acervos distribuídos pelo PNBE (BRASIL, 1997), por assim entendermos que esta política pública de leitura é uma importante mediadora na construção da prática leitora dos jovens alunos, e seus livros são importantes suportes para a propagação da literatura africana e afrobrasileira. Para nortear essa investigação, realizaremos um recorte metodológico: pautaremos nossos estudos nos livros literários destinados aos anos finais do ensino fundamental, buscando verificar, por meio da leitura das sinopses das narrativas, o protagonismo dado aos personagens negros, em especial às princesas negras africanas.

Consideramos o PNBE um importante canal de acesso a obras literárias por estudantes das escolas públicas, o qual visava democratizar o acesso a obras de literaturas brasileiras e estrangeiras infantis e juvenis, fornecendo materiais de pesquisas e de referência a professores e alunos das escolas públicas brasileiras. Além de constituir cada acervo com diferentes categorias de livros e diferentes gêneros de textos, os processos de seleção se pautavam por três critérios básicos: a qualidade textual, que se revela nos aspectos estéticos, literários e éticos; a estruturação narrativa, poética ou imagética; um vocabulário que não só respeite, mas, também amplie o repertório linguístico dos leitores da faixa etária correspondente a cada uma das edições do programa. Segundo Paiva e Soares (2014):

Os segmentos são atendidos em anos alternados, a qualidade temática, que se manifesta na diversidade e adequação dos temas, no atendimento aos interesses dos leitores, aos diferentes contextos sociais e culturais em que vivem e ao nível dos conhecimentos prévios que possuem; a qualidade 
gráfica, que se traduz na excelência de um projeto gráfico capaz de motivar e enriquecer a interação do leitor com o livro, e na qualidade estética das ilustrações; a articulação entre textos e ilustrações e o uso de recursos gráficos adequados aos leitores. Assim, todos os acervos de cada edição do programa, independente do segmento a ser atendido, são compostos por diversos gêneros literários, como: antologias poéticas brasileiras; antologia de crônicas; novelas ou romances brasileiros e estrangeiros (adaptados ou não); peças teatrais brasileiras ou estrangeiras; obras ou antologias de textos de tradição (PAIVA; SOARES, 2014, p. 15).

As distribuições dos acervos eram feitas de acordo com a quantidade de alunos matriculados nas escolas públicas. As escolas com até duzentos e cinquenta alunos recebiam um acervo; de duzentos e cinquenta a quinhentos alunos, dois acervos; de quinhentos e um a setecentos alunos, três acervos; e de setecentos e cinquenta a mil alunos, quatro acervos. Instituições com mais de mil e um alunos recebiam cinco acervos.

Dentre os gêneros mais recorrentes encontrados nos acervos mapeados estão a poesia, conto, crônica e romance. Além dos textos em verso, (poema, quadra, parlendas, cantigas, trava línguas, adivinhas) em prosa (pequenas histórias, novelas, contos, crônicas, textos de dramaturgia, memórias, biografias), livros de história em quadrinhos e obras clássicas da literatura universal.

De acordo com os editais do PNBE, no que diz respeito à compra de obras para serem distribuídas nas escolas, a principal prioridade na seleção dos títulos corresponde à ausência de estereótipos ou doutrinações. Compreendendo dessa maneira que o PNBE é um grande promotor no acesso à leitura, e as obras adotadas para compor os seus acervos serão fundamentais na construção da identidade leitora dos nossos jovens alunos, torna-se relevante fazer um levantamento de dados dos seus acervos nos anos de 2003, 2006, 2008, 2009, 2011 e 2013, anos estes nos quais os acervos foram destinados para as séries dos anos finais do ensino fundamental. Tomaremos como recorte as obras de literatura juvenil nas quais os protagonistas são personagens negros, especialmente as princesas negras. Organizaremos as obras encontradas em quadros e, por fim, as agruparemos de acordo com suas temáticas.

No ano de 2003 o PNBE distribuiu um acervo com dez coleções, formadas por quatro volumes de obras de literatura destinadas para os alunos da 8 série das escolas da rede pública. No catálogo de distribuição do ano acima referido foram localizados trinta e oito títulos, dentre os gêneros mais 
recorrentes presentes no acervo ${ }^{5}$ estão as crônicas, poemas, prosas e contos. Por meio da leitura das sinopses dos livros, descobrimos que, dos trinta e oito títulos distribuídos, apenas um traz personagem negro como protagonista: "Um sonho no caroço de abacate" (1995), de Moacyr Scliar, da Global Editora (BRASIL/FNDE, 2003).

Em 2006, foram distribuídos três acervos, formados por setenta e cinco títulos cada um. Percebemos que dos duzentos e vinte e cinco títulos selecionados pelo programa, apenas onze títulos trazem personagens negros como protagonistas. Os respectivos títulos encontrados seguem no Quadro 1.

Quadro 1 - Livros com personagens negros como protagonistas recomendados pelo PNBE de 2006.

\begin{tabular}{|l|l|l|}
\hline \multicolumn{1}{|c|}{ Títulos } & \multicolumn{1}{|c|}{ Autor (a) } & \multicolumn{1}{c|}{ Editora } \\
\hline $\begin{array}{l}\text { A Gênese Africana - contos, mitos e lendas da } \\
\text { Africa (2005) }\end{array}$ & Dinah de Abreu Azevedo & Landy Livraria Editora \\
\hline Comandante Hussi (2006) & Jorge Araújo & Editora 34 \\
\hline Costura de Nuvens (2006) & Adão Ventura & Editora Dubolsinho \\
\hline Histórias africanas para contar (2001) & Rogério Andrade Barbosa & Editora do Brasil - AS \\
\hline Leite do Peito (2001) & Geni Guimarães & Mazza Edições Ltda. \\
\hline Lendas Negras (2001) & Júlio Emílio Braz & Editora FTD \\
\hline O negro da chibata (2000) & Fernando Granato & Editora Objetiva \\
\hline O tesouro da Chica da Silva (2004) & Antônio Callado & Editora Objetiva \\
\hline Pedro Mico (2001) & Antônio Callado & Editora Nova Fronteira \\
\hline Sikulume e outros contos africanos (2005) & Júlio Emílio Braz & Pallas Editora \\
\hline Xixi na Cama (1979) & Drummond Amorim & Editora Dimensão \\
\hline
\end{tabular}

Fonte: BRASIL FNDE, 2006.

Em 2008, foram disponibilizados cinco acervos com vinte títulos cada. Constatamos que dos 
cem títulos selecionados, apenas onze obras possuem enredos cujos personagens protagonistas são negros. Os onze títulos encontrados são apresentados no Quadro 2.

Quadro 2 - Livros com personagens negros como protagonistas recomendados pelo PNBE de 2008

\begin{tabular}{|l|l|l|}
\hline \multicolumn{1}{|c|}{ Títulos } & \multicolumn{1}{|c|}{ Autor (a) } & \multicolumn{1}{c|}{ Editora } \\
\hline Chuva de manga (2005) & James Rumford & Brinque Book Editora de Livros \\
\hline Melhores amigas (2006) & Rosane Svartmantraz & Jorge Zahar Editor \\
\hline O cabelo de Lelê (2007) & Valéria Belém & Companhia Editora Nacional \\
\hline $\begin{array}{l}\text { O príncipe corajoso e outras histórias da Etiópia } \\
\text { (2007) }\end{array}$ & Praline Gay - Para & Edições SM \\
\hline $\begin{array}{l}\text { O que tem na panela } \\
\text { Jamela? (2007) }\end{array}$ & Wiki Daly & Edições SM \\
\hline $\begin{array}{l}\text { O rei preto de ouro preto } \\
\text { (2008) }\end{array}$ & Sylvia Orthof & Editora Gaia \\
\hline $\begin{array}{l}\text { Os chifres de Hiena e outras histórias da África } \\
\text { ocidental (2007) }\end{array}$ & MamadouDiallo & Edições SM \\
\hline Os gêmeos do tambor (2006) & $\begin{array}{l}\text { Rogério Andrade } \\
\text { Barbosa }\end{array}$ & DCL Difusão Cultural do Livro \\
\hline Os três presentes mágicos (2007) & $\begin{array}{l}\text { Rogério Andrade } \\
\text { Barbosa }\end{array}$ & Editora Record \\
\hline Outra vez (2005) & Ângela Lago & Editora RHF \\
\hline Ulomma, a casa da beleza e outros contos (2006) & Sunny & Paulinas Editora \\
\hline
\end{tabular}

Fonte: BRASIL/FNDE, 2008

No ano de 2009, foram distribuídos três acervos com aproximadamente cem títulos cada um. Verificamos que vinte títulos trazem o negro como protagonista. São, portanto, as vinte obras que estão dispostas no Quadro 3. 
Quadro 3 - Livros com personagens negros como protagonistas recomendados pelo PNBE de 2009

\begin{tabular}{|c|c|c|}
\hline Títulos & Autor (a) & Editora \\
\hline Agbalá, um lugar continente (2001) & Marilda Castanho & Cosac e Naify \\
\hline $\begin{array}{l}\text { As narrativas preferidas de um contador de } \\
\text { histórias (2007) }\end{array}$ & Ilan Brenman & $\begin{array}{l}\text { DCL Difusão Cultural do } \\
\text { Livro }\end{array}$ \\
\hline Benjamin o filho da felicidade (2007) & Heloísa Pires de Lima & Editora FTD \\
\hline Bom dia Camaradas! (2003) & Ondjaki & Agir Editora \\
\hline Chica e João (2008) & Nelson Cruz & Cosac e Naify \\
\hline $\begin{array}{l}\text { Contos e lendas afro-brasileiros - a criação do } \\
\text { mundo (2007) }\end{array}$ & José Reginaldo Prandi & Editora Schwarcz \\
\hline Do outro lado tem segredos (1987) & Ana Maria Machado & Editora Nova Fronteira AS \\
\hline Elégua (2007) & Carolina Cunha & Edições SM \\
\hline Estrela de Rabo e outras histórias doidas (2005) & Nilma Gonçalves & Frente Editora \\
\hline $\begin{array}{l}\text { Mãe África: mitos, lendas, fábulas e contos } \\
\text { (2008) }\end{array}$ & Celso Sisto & Pia Sociedade de São Paulo \\
\hline O fantasma de Tarrafal (2007) & Jean Yves Loude & Alis Editora \\
\hline $\begin{array}{l}\text { O papagaio que não gostava de mentira e } \\
\text { outras fábulas africanas (2008) }\end{array}$ & Adilson Martins & Pallas Editora \\
\hline $\begin{array}{l}\text { O segredo das tranças e outras histórias } \\
\text { africanas (2008) }\end{array}$ & $\begin{array}{l}\text { Rogério de Andrade } \\
\text { Barbosa }\end{array}$ & Editora Scipione \\
\hline Para conhecer Chica da Silva (2007) & Keila Grinberg (Org.) & Editora FTD \\
\hline Quem me dera ser feliz (2008) & Emilio Braz & Editora do Brasil \\
\hline Sundjata, o príncipe leão (1995) & $\begin{array}{l}\text { Rogério Andrade } \\
\text { Barbosa }\end{array}$ & $\begin{array}{l}\text { Ediouro Publicações de } \\
\text { Lazer e Cultura }\end{array}$ \\
\hline Tumbu (2007) & Marconi Leal & Editora 34 \\
\hline Uolace e João Victor (2004) & Rosa Amanda Straus & Landy Livraria Editora \\
\hline $\begin{array}{l}\text { Volta ao mundo dos contos nas asas de um } \\
\text { pássaro (2007) }\end{array}$ & Heitor Ferraz & Edições SM \\
\hline Zumbi, o ultimo herói dos Palmares (2005) & Carla Caruso & Instituto Calles \\
\hline
\end{tabular}

Fonte: BRASIL/FNDE, 2009.

No ano de 2011, foram disponibilizados três acervos, os quais compostos por cinquenta títulos, somando um total de cento e cinquenta obras distribuídas para as escolas. Foram localizados nove títulos que possuem personagens negros como protagonistas. O Quadro 4 os apresenta. 
Quadro 4 - Livros com personagens negros como protagonistas recomendados pelo PNBE de 2011.

\begin{tabular}{|l|l|l|}
\hline \multicolumn{1}{|c|}{ Títulos } & \multicolumn{1}{|c|}{ Autor (a) } & \multicolumn{1}{c|}{ Editora } \\
\hline Contos africanos dos países de língua portuguesa (2009) & Luandino Vieira (Org.) & Editora Ática \\
\hline Erinté, o caçador e outros contos africanos (2009) & Adilson Martins & Pallas Editora \\
\hline Histórias da tia Nastácia (2009) & Monteiro Lobato & Editora Globo \\
\hline Mzungu (2006) & MejaMwangi & Edições SM \\
\hline NyangaraChena - a cobra curandeira (2006) & Rogério Andrade Barbosa & Editora Scipione \\
\hline O Príncipe medroso e outros contos africanos (2009) & Anna Soler-Pont & Cia das Letras \\
\hline O Quilombo OrumAiê(2010) & André Diniz & Galera Record \\
\hline Omo-oba histórias de princesas (2009) & Kiusan de Oliveira & Mazza Edições \\
\hline Palmares, a luta pela liberdade (2009) & Eduardo Vetillo & Editora Cortez \\
\hline
\end{tabular}

Fonte: BRASIL/FNDE, 2011.

Ao verificarmos três os acervos do ano de 2013 , observarmos que dentre os sessenta títulos selecionados, apenas em oito os personagens protagonistas são negros. Vejamos os títulos a seguir no Quadro 5.

Quadro 5 - Livros com personagens negros como protagonistas recomendados pelo PNBE de 2013.

\begin{tabular}{|l|l|l|}
\hline \multicolumn{1}{|c|}{ Títulos } & \multicolumn{1}{c|}{ Autor (a) } & \multicolumn{1}{c|}{ Editora } \\
\hline A tatuagem- reconto do povo Luo (2012) & $\begin{array}{l}\text { Rogério de Andrade } \\
\text { Barbosa }\end{array}$ & Editora Gaivota \\
\hline Aqualtune e as histórias da África (2012) & Ana Cristina Massa & Editora Gaivota \\
\hline Comandante Hussi (2006) & Jorge Araújo & Editora 34 \\
\hline Kamazu (2011) & Carla Caruso \\
\hline O negrinho do Pastoreio (2012) & Sônia Junqueira & $\begin{array}{l}\text { Colégio Claretiano } \\
\text { Beneficente Editora }\end{array}$ \\
\hline O ônibus de rosa (2011) & Fabricio Silei & Edições SM \\
\hline Um sonho no caroço de abacate (1995) & Moacyr Scliar & $\begin{array}{l}\text { Global Editora e Distribuidora } \\
\text { LTDA }\end{array}$ \\
\hline Você é livre (2012) & Dominique Torrès & Cia das Letras \\
\hline
\end{tabular}

Fonte: BRASIL/FNDE, 2013

Após a leitura das sinopses dos livros escolhidos para compor os acervos do PNBE, constatamos que, dentre os novecentos e noventa e seis títulos selecionados, apenas sessenta títulos 
trazem personagens negros como protagonistas. Para fins de análise, dividimos as obras em cinco categorias: narrativas com personagens negros, narrativas que retomam importantes nomes da história de luta do povo negro, narrativas sobre a identidade afro-brasileira, narrativas africanas e narrativas com histórias de princesas. É válido ressaltar que os termos africanos e afro-brasileiros são entendidos da seguinte forma: africanos são os personagens que nasceram e viveram no continente africano; já os afro-brasileiros são personagens que nasceram e vivem no Brasil, mas que por meio da caracterização realizada pelo narrador apresentam raízes africanas.

Então, dentre os sessenta títulos localizados, treze narrativas protagonizam personagens negros, mas não apresentam especificidades da cultura africana ou afro-brasileira. As obras abordam temáticas que discutem sobre o preconceito e de como os personagens lutam para reverter essa realidade. São esses títulos, a saber: Xixi na cama (1979); Um sonho no caroço de abacate (1995); Leite do Peito (2001); Uolace e João Victor (2004); Outra Vez (2005); Estrela de Rabo e outras histórias doidas (2005); Costura de Nuvens (2006); Melhores Amigas (2006); Benjamin o filho da felicidade (2007); Quem me dera ser feliz (2008); Histórias da tia Nastácia (2009); Kamazu (2011); O ônibus de rosa (2011).

Nos acervos mapeados, oito obras retomam a história de luta do povo negro por meio do relato de biografias de importantes nomes deste movimento. São eles: 0 negro da chibata (2000); Pedro Mico (2001); O tesouro da Chica da Silva (2004); Zumbi, o último herói dos Palmares (2005); Para conhecer Chica da Silva (2007); Chica e João (2008); Palmares, a luta pela liberdade (2009); 0 negrinho do pastoreio (2012).

As narrativas que remetem à identidade afro-brasileira, seja por questões estéticas, como tipo de cabelo ou por relações de origem e cultura existentes entre Brasil e África somam um total de onze títulos. São os títulos: $\mathbf{O}$ cabelo de Lelê (2007); O que tem na panela Jamela? (2007); O rei preto de ouro preto (2008); O fantasma de Tarrafal (2007); As narrativas preferidas de um contador de histórias (2007); Tumbu (2007); Do outro lado tem segredos (1980); Volta ao mundo dos contos nas asas de um pássaro (2007); Agbalá, um lugar continente (2001); Contos e lendas afro-brasileiros - a criação do mundo (2007); O Quilombo Orum Aiê (2010).

Estão inseridos nas temáticas africanas vinte e quatro títulos, tais narrativas retomam a oralidade da África por meio de mitos, lendas e contos. São os títulos: Sundjata, o príncipe leão (1995); Histórias africanas para contar (2001); Lendas Negras (2001); Bom dia camaradas! (2003); A Gênese 
Africana - contos, mitos e lendas da África (2005); Chuva de manga (2005); Sikulume e outros contos africanos (2005); Comandante Hussi (2006); Mzungu (2006); Nyangara Chena - a cobra curandeira (2006); Os gêmeos do tambor (2006); Ulomma, a casa da beleza e outros contos (2006); Os três presentes mágicos (2007); Os chifres de Hiena e outras histórias da África ocidental (2007); Elégua (2007); O príncipe corajoso e outras histórias da Etiópia (2007); Mãe África: mitos, lendas, fábulas e contos (2008); O segredo das tranças e outras histórias africanas (2008); O papagaio que não gosta de mentira e outras fábulas africanas (2008); Contos africanos dos países de língua portuguesa (2009); Erinté, o caçador e outros contos africanos (2009); O Príncipe medroso e outros contos africanos (2009); A tatuagem - reconto do povo Luo (2012); Você é livre (2012). Por fim, ao longo de todo o acervo do PNBE que foi pesquisado, localizamos apenas duas obras com princesas africanas. São elas: Omo - oba histórias de princesas (OLIVEIRA, 2009) e Aqualtune e as histórias da África (MASSA, 2012).

Após uma análise inicial dos acervos do PNBE, verificamos que a Lei 10.639/03 impulsionou políticas públicas de leitura a adotarem em seus acervos obras com temáticas africanas e afrobrasileiras. Constatamos que, embora os números de títulos com personagens negros sejam inferiores em relação às demais obras adotadas pelo programa, e embora em escala menor que a esperada, é possível afirmar que essa política de distribuição de livros conseguiu se adequar às exigências da lei. Reconhecemos a importância do PNBE como um programa de leitura de considerável contribuição para o acesso a livros literários por alunos das escolas públicas, além de possuir um papel fundamental na propagação da cultura e da história de povos pouco conhecidos. Segundo Ramos e Amaral (2015):

A definição por uma determinada obra para compor um acervo que estará
em bibliotecas de escolas públicas de um país é uma decisão política acerca
da valorização de determinada cultura, a qual passará a constituir também a
identidade dos leitores [...]. A opção por obras que privilegiem culturas
diversas, entre elas a africana, é uma forma de permitir que as crianças
construam seu imaginário com imagens provindas de várias culturas. Abrir
espaço e acolher outras, outras culturas nas leituras a serem feitas pela
criança brasileira é, pois, uma tentativa de contribuir para que o discurso
literário seja de fato dialógico, de modo que não se tenha uma história única
circulando no imaginário dos estudantes. Temos tantas histórias quantos são
os seus narradores, quantas são as culturas privilegiadas. Trata-se de uma
iniciativa que busca apagar o discurso monológico em prol das outras vozes
que compõem o cenário nacional (RAMOS; AMARAL, 2015, p. 204).

Por meio do levantamento realizado na pesquisa, comprovou-se que a distribuição dos 
acervos do PNBE foi concretizada, alcançando um considerável número de alunos em diversas escolas públicas. Entretanto, apesar das crescentes publicações e da efetividade nas distribuições, ainda presenciamos uma escassez do ensino sobre essas temáticas, algo que se origina a partir de resistência de professores em trabalhar tais conteúdos e de alunos que parecem não se identificar com essa recém-adotada literatura. Cagneti e Silva (2013) afirmam que, assim como um dia se começou a exigir das escolas que lidassem com a literatura para crianças e jovens, sem que seus professores estivessem preparados para isto, hoje se repete a mesma situação em relação ao ensino dessas culturas.

No que concerne às orientações para o trabalho com essas temáticas, verificarmos que o ensino da literatura afro-brasileira está presente dentre os mais importantes documentos norteadores de práticas educacionais. Ao realizarmos a leitura dos Parâmetros Curriculares Nacionais - PCN's (BRASIL, 1997) e as versões da Base Nacional Comum Curricular - BNCC (BRASIL, 2017), verificamos uma progressão no direcionamento para o trabalho com os livros literários em sala de aula, revelando adequação frente à Lei 10.639/03. Contudo, entendemos que para o efetivo uso dessas obras, tão importante quanto as orientações para o corpo docente e a presença das obras nas bibliotecas, é o investimento em projetos que prezem pela formação desses professores que atuam diariamente em sala de aula e receberam em suas escolas as obras.

Entendemos que ainda há uma longa trajetória a ser percorrida para que se alcance a consolidação das temáticas africanas na literatura brasileira e para que isto seja possível, antes é preciso não apenas incluir a imagem das princesas africanas, mas valorizar por meio da representação desses personagens a cultura da África, de maneira que venha a contribuir para a propagação de forma positiva das histórias dessas princesas ainda pouco conhecidas. Oliveira (2008) afirma:

Não basta, portanto, a mera inclusão no mercado editorial e no espaço
escolar de produções literárias que apresentam protagonistas negros (as), ou
que delineiam as religiosidades de matrizes africanas, a cultura afro-
brasileira, o continente africano e temáticas afins. Diante da propagação da
inferiorização do segmento étnico-racial negro nos materiais didáticos e na
literatura, mais ainda é necessário, na atualidade, redobrarmos a atenção em
relação às produções nesse enfoque, pois, em virtude da Lei 10.639/03, a
tendência é que haja investimento no mercado editorial, culminando com
publicações e reedições nem sempre elaboradas com a devida qualidade
estética e temática, no tocante à história e cultura africana e afro-brasileira,
conforme exigência das Diretrizes Curriculares Nacionais (2005) que
regulamentam a aludida lei (OLIVEIRA, 2008, p. 2).

Reconhecemos a importância da recente inclusão das histórias das princesas negras africanas 
nas narrativas infantis e juvenis, porém ressaltamos a importância de se manter uma atenção redobrada no tocante à qualidade destas obras que estão promovendo a "representatividade" das histórias africanas para o público infantil e juvenil brasileiro.

\section{As princesas africanas na literatura juvenil: uma análise dos títulos encontrados}

A partir das pesquisas realizadas nos acervos do PNBE, encontramos duas obras com adaptações das histórias de princesas africanas. Tais publicações serão analisadas a seguir para examinarmos a qualidade literária com temáticas africanas. Como já anunciado anteriormente, os títulos são: Omo - oba histórias de princesas (OLIVEIRA, 2009) e Aqualtune e as histórias da África (MASSA, 2012).

Inicialmente, estabelecemos como critérios para nossa análise a averiguação dos elementos que constituem essas narrativas (personagens, cenários e enredos), os diálogos existentes entre os textos visuais e verbais, observando como são realizadas as caracterizações das princesas. Pontuaremos, ainda, as contribuições que as histórias narradas estão trazendo para o reconhecimento da cultura africana.

As obras que aqui serão tratadas são personificações de culturas, tradições e crenças e se manifestam por meio de lendas ${ }^{6}$ e mitos. Cada obra se torna um canal de conhecimento sobre as histórias das princesas africanas, não necessariamente, estas narrativas apresentarão as mesmas características, pois o continente que aqui é tratado possui uma considerável diversidade cultural e isto o torna praticamente impossível de ser representado da mesma maneira.

\section{Apresentando as narrativas}

O livro Omo-Oba: Histórias de Princesas (OLIVEIRA, 2009), escrito por Kiusam de Oliveira e ilustrado por Josias Marinho, reconta mitos africanos divulgados na tradição ketu e que reforçam os diversos modos de ser femininos. A narrativa é dividida em seis mitos e relata as histórias de Oiá, Oxum, lemanjá, Olocum, Ajê e Xalugá e Oduduá. As princesas apresentadas nesse livro são seis 
divindades iorubanas, orixás, cujas histórias de seus poderes são recontadas como se fosse no tempo da infância delas. Essas histórias tratam de dons especiais de divindades que muitas vezes precisam se separar do grupo para poder vivê-los com integridade como é o caso de Oiá e de Olocum e também dos que precisam de um grupo para se realizar. Por exemplo, lemanjá de cuja boca nascem os seres do mar e outros orixás ou Oxum cuja presença tem a magia necessária para reintegrar Ogum.

Em Aqualtune e as histórias da África (MASSA, 2012), somos apresentados à história de Maria, Guilherme e Aqualtune, que só queria ser chamada de Alice, três adolescentes que vão viajar para uma fazenda longe da cidade. A fazenda pertencia aos avós de Maria e se localiza na Serra da Barriga, em Alagoas - cenário que faz parte de um contexto de escravidão que ocorrera há muitos anos atrás, mais precisamente no século XVII. Os adolescentes acreditavam que o ponto alto da viagem seria caçar vagalumes, mas na verdade estavam prestes a embarcar em uma grande aventura que transformaria suas vidas para sempre. Tudo se inicia, quando no antigo casarão, que havia sido um engenho de cana-de-açúcar, o trio conhece Vó Cambinda que é cozinheira, e seu bisneto Kafil. Eles moram em uma vila e são descendentes de escravos. Ao conhecer e participar um pouco mais da cultura quilombola, Alice descobre ser peça importante de uma antiga lenda africana sobre a princesa Aqualtune e junto com seus amigos enfrenta as forças da natureza e vão em busca da verdade por trás dessa antiga lenda.

\section{Os elementos que as constituem}

Inicialmente, retomamos informações que nos situam sobre um novo aspecto o qual assume a literatura juvenil. Essa, já que endereçada a um público com uma bagagem de leitura mais elevada e em uma fase em que o universo imaginário já foi realizado, agora se propõe a retratar contextos que permitam ao leitor o contato com o real. Os temas e assuntos abordados não necessariamente precisarão carregar a ideia de um conteúdo mais leve; os cenários tornam-se cada vez mais reais, os personagens representam vivências próximas dos seus leitores. Porém, o aspecto mais marcante nessa caracterização diz respeito ao protagonismo dos personagens principais.

Os personagens que compõem as duas narrativas aqui apresentadas são princesas, príncipes, reis, guerreiros (as) e orixás. Diferentes dos contos populares tradicionais, as mulheres africanas não são princesas como estamos acostumados a conhecer. São outros tipos de princesas, são de reinos diferentes, onde não existem castelos, torres e vestidos longos. E, ao contrário da maioria das narrativas clássicas, nessas nem sempre os finais são felizes. 
Outra diferença se configura em relação ao modelo de princesa tradicional, que costuma ser caracterizado como figuras passivas e que dependem de outros personagens para libertá-las. Contrapondo-se a esse modelo, as princesas africanas são caracterizadas como sendo independentes, fortes e corajosas. Elas enfrentam obstáculos com suas próprias forças e por este motivo são descritas como Princesas Guerreiras.

Outra figura comum nos contos clássicos são os príncipes, estes sempre recebem um grande protagonismo, pois são os responsáveis por matar dragões, invadir torres e castelos e resgatar as princesas. Porém, nas duas narrativas apresentadas, os príncipes recebem um protagonismo secundário. Na história de Aqualtune, ele nem ao menos é mencionado, já em Omo - oba histórias de princesas (OLIVEIRA, 2009) o mito Oduduá e a briga pelos sete anéis revela um duelo entre o príncipe e a princesa pela autoridade no relacionamento. O príncipe exige que a princesa cumpra as suas exigências, porém, ela não aceita suas imposições e reivindica seu lugar.

No que diz respeito à figura do Rei, em Aqualtune, este é mencionado brevemente e de certa forma não assume nenhum papel decisivo para a construção da narrativa. Ele apenas é rememorado nos momentos em que o narrador explica sobre a invasão dos portugueses ao reino africano, a qual Aqualtune pertencia. Durante essas batalhas, o rei, pai de princesa, foi morto e sua filha presa acabou sendo transportada em navios negreiros, vendida como escrava no Brasil.

As figuras maternas dessas princesas não são mencionadas. Na história de Aqualtune, a própria princesa já chegou grávida, ao Brasil, pois foi comprada como escrava reprodutora. Nessa narrativa, percebemos que os laços afetivos familiares são apagados. Já nos mitos recontados por Kiusam de Oliveira verificamos que alguns laços familiares são mantidos, mas em sua grande maioria as princesas se tornam independentes.

Madrastas, bruxas e dragões inexistem nessas histórias. Em Aqualtune, as figuras "malvadas" são substituídas por invasores portugueses e senhores de escravos. Percebemos que os vilões perdem um aspecto fantasioso e são aproximados da realidade vivenciada pela princesa. Em Omo - oba histórias de princesas (OLIVEIRA, 2009), a maldade não é apresentada mediante outras pessoas, pois o perigo, neste caso, habita dentro das princesas.

Ao apontarmos a permanência dos personagens como príncipes e princesas é bem possível que imediatamente tenhamos imaginado os castelos em que essas histórias se passaram, mas esse é outro elemento que sofre alteração. Sabemos que as princesas aqui referidas são de origens africanas, 
logo, se as obras se propõem a retratar os aspectos destas culturas e dos momentos históricos em que elas estiveram inseridas, precisará criar cenários que retratem estas realidades as que se pretende expor. Dessa forma, a narrativa de Aqualtune se desenvolve em tribos, fazendas e senzalas. Percebemos nessa primeira descrição de cenários que há uma ligação de culturas que fica aqui evidenciada: as tribos se referem à configuração dos reinos africanos e as fazendas e senzalas são retratos do período de escravidão no Brasil. Omo - oba histórias de princesas (OLIVEIRA, 2009) se passa em florestas e mares, os cenários estão sempre de acordo com a locais de origem das princesas.

\footnotetext{
O aspecto moralizante das obras ainda é notado em alguns trechos. Em Aqualtune e as histórias da África (MASSA, 2012), observamos isto quando vó Cambinda repreende Alice no momento em que ela não quer mais ouvir as lendas que estão sendo contadas:

Não desconfie do que você não conhece. Aprenda, escute, sempre temos o que aprender. O que você está vendo aqui é uma cultura diferente da sua, nós somos descendentes dos irmãos africanos, temos outros hábitos, não é ruim, é diferente (MASSA, 2012, p. 49).
}

Percebemos que essa repreensão transmite uma mensagem que ressalta a importância de ouvir, antes de opinar. Sobretudo, nesse caso, as informações estão sendo dadas por uma pessoa bem mais velha e se referem a uma cultura desconhecida. Se negar a ouvi-la seria uma desobediência e também se configuraria como falta de respeito. Em Omo - oba histórias de princesas (OLIVEIRA, 2009), os mitos deixam mensagens sobre a importância de respeitar os limites para que o dom que as princesas possuem não cause dano a si e aos outros.

\section{Os diálogos entre o texto verbal e visual}

O livro Aqualtune e as histórias da África (MASSA, 2012) é composto por poucas ilustrações. A primeira imagem surge na capa (Figura 1) na qual uma mulher é ilustrada com um turbante na cabeça e com uma lança na mão. Notamos que a roupa é composta por estampas de plantações de cana-deaçúcar, imagem que faz alusão aos engenhos em que os negros eram escravizados. A região da Serra da Barriga, em Alagoas, cenário em que a narrativa se passa, possui um contexto histórico ligado ao cultivo de cana-de-açúcar. Pernambuco, inclusive, chegou a ser considerada uma das mais ricas capitanias durante o ciclo açucareiro. Esse cultivo se passa entre meados do século XVI e meados do século XVIII e representou, durante muito tempo, a base da economia agrícola e industrial do Brasil colonial. Os senhores de engenho, para ampliar e exportar sua produção, utilizava mão de obra escrava composta por africanos, cujo tráfico também gerava lucros. 


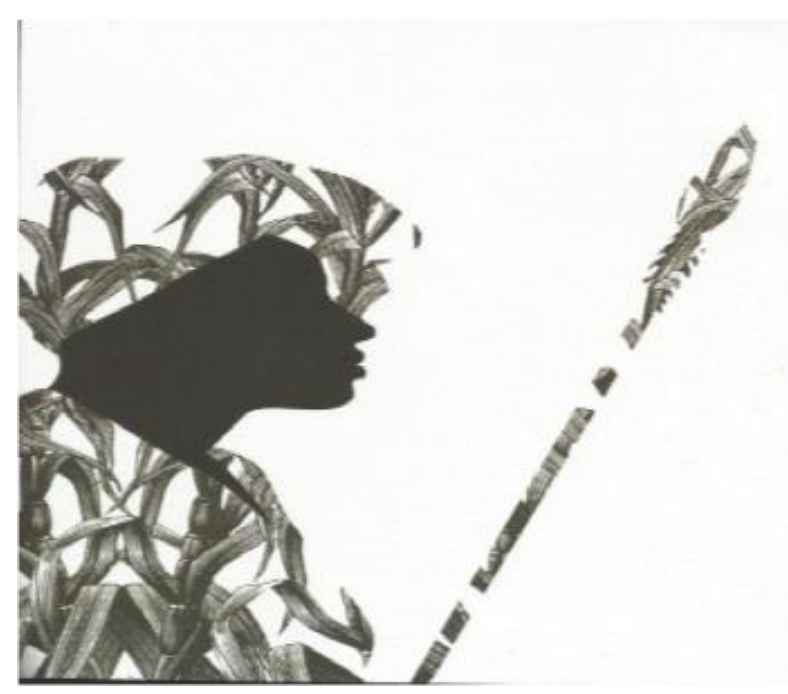

Figura 1 - Aqualtune, a princesa guerreira. Fonte: Arquivo pessoal (Massa, 2012).

Observamos na ilustração exemplificada na Figura 1, uma mulher sem expressão no rosto. As cores presentes no turbante se repetem nas entradas dos capítulos. A paleta de cores também é bastante reduzida em que predominam as cores cinza e preto. No texto verbal, Aqualtune é descrita como uma negra, linda, forte, guerreira, pernas longas, compridas, corpo musculoso, protegia o reino dos invasores e era querida por todos. "Os cabelos ficavam sempre presos e arrumados como devem ser os cabelos de uma princesa" (MASSA, 2012, p. 46). Representava seu povo não por ser uma princesa que fazia parte da nobreza, mas por em diversas situações se fazer semelhante aos demais membros do seu reino. Em Massa (2012, p. 46), encontramos a seguinte descrição: “Só sabia lutar sem os enfeites no corpo. Na hora de lutar, ela não era a princesa, a filha do rei, com mais importância do que os outros. Era igual às guerreiras mulheres, lutando para defender o reino do Congo".

A escritora e ilustradora Ana Cristina Massa nos mostra que a história de Aqualtune tornouse uma lenda graças a um mapa, uma estátua e uma tiara. A princesa do reino do Congo atravessou gerações e ainda se faz viva entre os descendentes do povo africano.

O texto escrito ainda reforça a coragem de Aqualtune em três ocasiões: a primeira, diz respeito à luta pela defesa do seu reino que vivia em guerras constantes. A segunda, se passa quando o reino da princesa é dominado pelos portugueses e ela precisa fugir enfrentando vários perigos. E a terceira, se dá quando Aqualtune chega ao Brasil como escrava e, em seguida, foge para o Quilombo dos Palmares, o qual abriga muitos negros escravizados que também decidem fugir em busca da liberdade. 
A história da princesa retratada na obra Aqualtune e as histórias da África (MASSA, 2012), só recebe protagonismo a partir de um resgate de objetos simbólicos (mapa, tiara e estátua) que são encontrados por três adolescentes. Nessa narrativa que retoma ligações com antepassados no cumprimendo de uma lenda, a história real da princesa do reino do Congo, Aqualtune, fica como pano de fundo diante das aventuras vivenciadas por Alice, Maria, Guilherme e Kafil.

Em Omo - oba histórias de princesas (OLIVEIRA, 2009), localizamos algumas ligações entre os textos verbais e visuais. Inicialmente nos atentamos em observar os traços estéticos das princesas: beleza, vaidade, graciosidade, rapidez e genialidade são características atribuídas às seis princesas. Vejamos esses traços na Figura 2

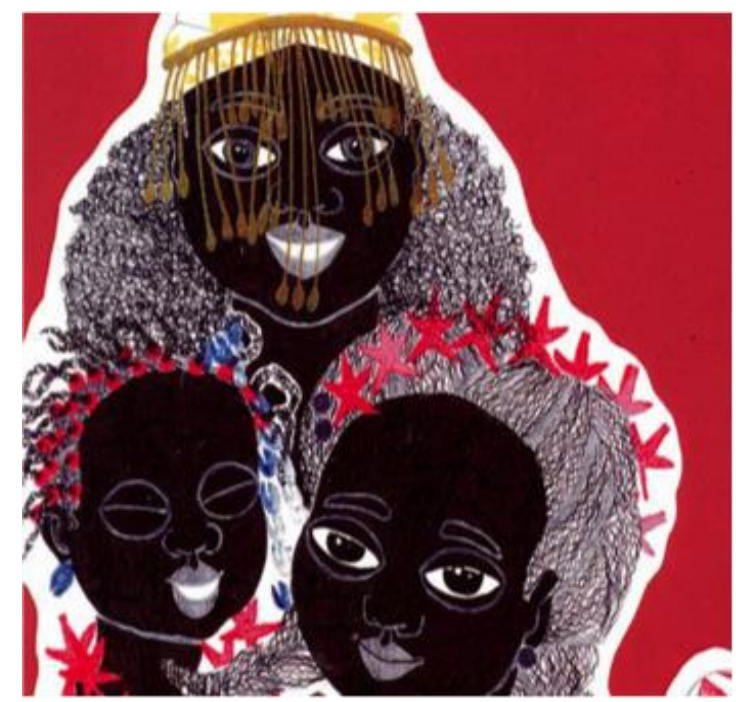

Figura 2 - Histórias de princesas. Fonte: Arquivo pessoal (Oliveira, 2009).

$\mathrm{Na}$ Figura 2, podemos visualizar alguns dos traços estéticos evidenciados durante toda a narrativa, especialmente, a vaidade - coroas, brincos, tiaras etc. O cabelo crespo também vem marcado na ilustração. As imagens evidenciam a doçura no olhar das princesas e a felicidade sempre apresentada por meio dos sorrisos. Verificamos que o ilustrador, Josias Marinho, se apossa de uma paleta de cores bem mais ampla que as da Figura 1. As cores selecionadas para ilustrar as páginas dos livros são modificadas de acordo com cada mito. Isso acontece pelo fato de cada princesa ter preferência por cores distintas e também pertencerem a povos distintos.

Por meio da leitura e análise das características apresentadas no modelo das princesas africanas, percebemos o quão forte são as marcas dos costumes e tradições de cada uma delas. A 
partir disso, selecionamos nas duas narrativas as principais representações que elas enfatizam sobre as culturas, tradições e religiões nos diferentes contextos dos reinos africanos.

\section{Os reflexos das tradições africanas}

As duas narrativas são representações de crenças e culturas que já existiram e que deixaram suas marcas na contemporaneidade. Na leitura das obras, um aspecto se torna comum entre elas: a relação dos povos com a natureza e as divindades africanas. De acordo com Domingos (2011):

Os homens da religião tradicional africana respeitam profundamente a natureza. [...] na relação entre o homem e a natureza, o indivíduo não é um sujeito abstrato, separado, independente das condições ecológicas da sua existência. $O$ indivíduo não está separado das condições genealógicas e de seus pressupostos míticos, místicos, mágicos ou religiosos (DOMINGOS, 2011, p. 7).

Outra tradição pertencente à cultura africana que é retomada durante a narrativa Aqualtune e as histórias da África (MASSA, 2012), diz respeito à importância da figura dos anciãos, sobre os quais recai a legitimidade de ser dominador de conhecimentos. Podemos confirmar essa personificação a partir da importante figura representada pela velha Cambinda: ela é uma fonte de histórias das lendas locais e ainda é uma líder em sua comunidade por ser a pessoa mais velha e sábia. Vó Cambinda não só é a guardiã do saber, como também promove, por meio da contação de histórias, o reencontro entre memória e tradição. Ela carrega uma das mais importantes heranças africanas: a oralidade. Por meio de suas histórias, ela incute aos mais jovens o conhecimento e a sabedoria, valores estes que se propagam entre as gerações:

O fato é que as narrativas sempre fizeram e fazem parte da nossa essência. Nossos antepassados de tradição oral, por exemplo, se utilizavam da narração de contos para repassar de geração a geração toda sabedoria e todo conhecimento adquirido e acumulado pelo povo, ao longo do tempo. Por intermédio da palavra e da poética dos contadores tradicionais, representados por anciãos, griôs, artesãos e pessoas da comunidade, tais contos eram disseminados e narrados à população. Da boca desses narradores, ou seja, do próprio povo é que os ensinamentos, valores, costumes, organização social, memória e identidade coletiva eram repassados, armazenados e transmitidos a seus descendentes (SILVA, 2015, p. 19).

Entre os povos africanos, há uma idealização de que as sabedorias pertencem às pessoas 
mais velhas. Esse dado é reforçado em uma matéria intitulada Anciãos: os pilares da África (2002), realizada por León Ngoy kalumba:

Os anciãos em África desde sempre desempenharam um papel decisivo. Além de fundamento da família e da etnia, eram os condutores da vida, o elo de união entre o passado e o futuro, os repositórios da sabedoria popular e os educadores da juventude (KALUMBA, 2002, p. 1).

Assim sendo, os anciãos são também a memória do povo, aqueles que preservam a história e uma infinidade de acontecimentos e palavras recebidos do passado. Em seus estudos, Domingos $(2011$, p. 6) reforça que "O passado confere autoridade àquele que traz o peso do tempo, da sabedoria, da geração e da ancestralidade".

A partir das análises, apontamos que esses livros direcionados ao público juvenil resgatam aspectos que mostram as peculiaridades das culturas africanas. Esse resgate proporciona que os jovens leitores conheçam essas riquezas e tenham contato com esse universo de crenças e tradições tão pouco explorado.

\section{Considerações finais}

Ao darmos início sobre a exposição dos principais objetivos deste artigo, indicamos que direcionaríamos nossas investigações para as representatividades dos personagens negros, especialmente das princesas africanas, nos acervos do PNBE. Durante esta investigação, a constatação de um dado se tornou bastante relevante, vimos que ao longo dos levantamentos bibliográficos houve um progressivo aumento de obras com protagonistas negros. Também observamos que o protagonismo direcionado aos personagens negros só passou a ganhar uma considerável progressão a partir da lei 10.639/03 (BRASIL, 2003), em que as políticas públicas de leituras, visando cumprir às exigências dispostas na lei, se apropriaram desses temas e aumentaram títulos de obras nos acervos.

Entretanto, um dos grandes impasses no que diz respeito à adoção das obras de literatura afro-brasileira em sala de aula diz respeito à falta de clareza que professores e alunos possuem sobre essas narrativas. Durante a análise e observação dos documentos que norteiam as práticas educacionais docentes, como os PCN's (BRASIL, 1997) e a BNCC (BRASIL, 2017), constatamos que as orientações para os professores estão dispostas entre os principais objetivos desses documentos.

A partir dessas verificações, podemos concluir que a ausência da literatura afro-brasileira na 
sala de aula não está ligada à falta de orientações nos documentos educacionais, pois elas existem. Sobretudo, para que elas sejam postas em prática, é necessária a efetivação de um trabalho coletivo em que o mercado editorial, em parceria com os escritores brasileiros, elaborem materiais com qualidade estética e literária; os programas de distribuição de livros permaneçam analisando criteriosamente os títulos selecionados; os acervos continuem chegando às escolas; e professores e bibliotecários, enquanto mediadores de leitura, sejam orientados, por meio dos documentos norteadores e de formação continuada, para que tenham clareza sobre o trabalho que podem desenvolver com práticas de leitura com os livros e o ensino da literatura afro-brasileira.

Outro dado apontado durante as nossas pesquisas foi a baixa representatividade das obras com princesas negras africanas. A partir dessa constatação, levantamos alguns apontamentos que talvez possam nos esclarecer sobre essas ausências. O primeiro diz respeito ao baixo número de escritores que estão propondo contar essas histórias; o segundo é que, de certa maneira, ainda estamos vinculados às representações das princesas europeias, o que é bastante considerável, pois temos séculos de tradições dessas narrativas e apenas treze anos desde que a lei 10.639/03 foi homologada no país e propôs o resgate das histórias africanas esquecidas. Segundo Traça (1998), essa tradição se constituiu por meio dos escritos de Charles Perrault (1628-1703), Jacob Grimm (17851863), Wilhelm Grimm (1786-1859) e Hans Christian Andersen (1805-1875) e da indústria cultural. Não seria possível mencionar essa indústria sem nos referirmos a Walt Disney (1901-1966), responsável por apresentar às crianças as representações frágeis, estereotipadas e cheias de encantamento das princesas (TRAÇA, 1998).

Durante o levantamento dos acervos do PNBE, nos deparamos com narrativas escritas por brasileiros que estão adaptando os contos populares africanos e revelam as histórias das princesas que existiram, mas que ficaram esquecidas e apagadas na nossa história e memória. Reconhecemos que as leituras dessas obras contribuem de maneira significativa para o reconhecimento das princesas africanas e da cultura do povo africano. Porém, ressaltamos que, ainda, há um longo caminho a ser percorrido para a consolidação da identidade dessas princesas na literatura juvenil brasileira. 


\section{Referências}

BRASIL. Parâmetros Curriculares Nacionais. Brasília: MEC/SEB, 1997.

. Lei no. 10.639, de 9 de janeiro de 2003. Brasília, 2003. Disponível em: <http://www.planalto.gov.br/ccivil 03/leis/2003/L10.639.htm>. Acesso em: 05 nov. 2017.

Ministério da Educação. Fundo Nacional de Desenvolvimento da Educação. Programa Nacional Biblioteca na Escola. Literatura em minha casa. Brasília: MEC/SEB, 2003. Disponível em:

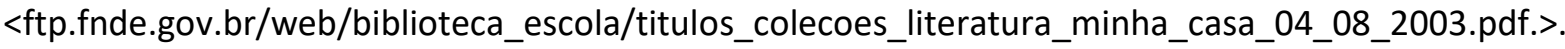
Acesso em: 05 nov. 2017.

. Ministério da Educação. Fundo Nacional de Desenvolvimento da Educação. Programa Nacional Biblioteca na Escola. Acervos (PNBE). Brasília: MEC/SEB, 2006. Disponível em: $<$ http://portal.mec.gov.br/programa-nacional-biblioteca-da-escola/acervos>. Acesso em: 05 nov. 2017.

Ministério da Educação. Fundo Nacional de Desenvolvimento da Educação. Programa Nacional Biblioteca na Escola. Acervos (PNBE). Brasília: MEC/SEB, 2008. Disponível em: $<$ http://portal.mec.gov.br/programa-nacional-biblioteca-da-escola/acervos $>$. Acesso em: 05 nov. 2017.

Ministério da Educação. Fundo Nacional de desenvolvimento da educação. Programa Nacional Biblioteca na Escola. Acervos (PNBE). Brasília: MEC/SEB, 2009. Disponível em: $<$ http://portal.mec.gov.br/programa-nacional-biblioteca-da-escola/acervos>. Acesso em: 05 nov. 2017.

Ministério da Educação. Fundo Nacional de desenvolvimento da educação. Programa Nacional Biblioteca na Escola. Acervos (PNBE). Brasília: MEC/SEB, 2011. Disponível em: $<$ http://portal.mec.gov.br/programa-nacional-biblioteca-da-escola/acervos>. Acesso em: 05 nov. 2017.

. Ministério da Educação. Fundo Nacional de Desenvolvimento da Educação. Programa Nacional Biblioteca na Escola. Acervos (PNBE). Brasília: MEC/SEB, 2013. Disponível em: <http://portal.mec.gov.br/programa-nacional-biblioteca-da-escola/acervos>. Acesso em: 05 nov. 2017.

Base Nacional Comum Curricular. Brasília: MEC/SEB, 2017. Disponível em: <http://basenacionalcomum.mec.gov.br/images/BNCCpublicacao.pdf>. Acesso em: 05 nov. 2017.

CAGNETI, S. S. Literatura infantil juvenil: diálogos Brasil-África. Belo Horizonte: Autêntica Editora, 2013. (Série Conversas com o Professor, 3).

DOMINGOS, L. T. A visão africana em relação à natureza. Revista brasileira de história das religiões. v. III, n. 9, p. 1-11, 2011.

KALUMBA, L. N. Anciãos: os pilares da África. Revista Além Mar, out. 2002. Disponível em: <http://www.alem-mar.org/cgibin/quickregister/scripts/redirect.cgi?redirect=EEFIAZZpuFgpqgltZb>. Acesso em: 05 nov. 2017. 
MASSA, A. C. Aqualtune e as histórias da África. São Paulo: Gaivota, 2012.

NASCIMENTO, I. A leitura como moeda de trânsito social: entrevista com Marisa Lajolo. In: CARVALHO, P. B. Políticas e práticas de leitura no Brasil. São Paulo: Ação Educativa/Observatório da Educação e Juventude, 2003. (Série Em Questão, 2). p. 47-57.

OLIVEIRA, M. A. J. Literatura afro-brasileira infanto-juvenil: enredando inovação em face à tessitura dos personagens negros. In XI Congresso Internacional da ABRALIC: Tessituras, Interações, Convergência, 11., 2008, São Paulo. Anais... São Paulo: USP, 2008. Disponível em: <http://www.abralic.org.br/eventos/cong2008/AnaisOnline/>. Acesso em: 27 nov. 2017.

OLIVEIRA, K. Omo-Oba: histórias de princesas. Belo Horizonte: Mazza Edições, 2009.

PAIVA, A.; SOARES, M. PNBE na escola: literatura fora da caixa. Brasília: MEC/SEB, 2014. Disponível em: <http://portal.mec.gov.br/index.php?option=com docman\&view=download\&alias=15609-guiaei-leituraforadacaixa-pdf\&category slug=maio-2014-pdf\&ltemid=30192>. Acesso em: 05 nov. 2017.

RAMOS, F. B.; AMARAL, L. M. Diversidade na sala de aula: representação da cultura afro-brasileira. Revista Eletrônica de Educação. v. 9, n. 2, p. 301-319, 2015.

SILVA, V. S. Foi assim que me contaram, foi assim que te contei: diálogos e reflexões sobre a narração de histórias. In: SOUZA, R. J. (Org.), A arte narrativa na infância - práticas para o teatro da leitura e a contação de histórias. Campinas: Mercado de Letras, 2015. p. 17-26.

TRAÇA, M. E. O Fio da Memória - Do Conto Popular ao Conto para Crianças. 2. ed. Porto: Porto Editora, 1998. 